\title{
Short Communication \\ Dietary intakes of carotenoids and other nutrients in the risk of nasopharyngeal carcinoma: a case-control study in Italy
}

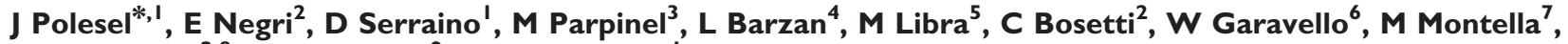 \\ C La Vecchia ${ }^{2,8}$, S Franceschi ${ }^{9}$ and R Talamini' \\ 'Unit of Epidemiology and Biostatistics, Centro di Riferimento Oncologico, IRCCS, Via F. Gallini 2, 3308I Aviano, Italy; ${ }^{2}$ Departement of Epidemiology, \\ Istituto di Ricerche Farmacologiche Mario Negri, 20156 Milan, Italy; ${ }^{3}$ Istituto di Igiene ed Epidemiologia, Università degli Studi di Udine, 34 I00 Udine, \\ Italy; ${ }^{4}$ Department of Head and Neck Surgery, Azienda Ospedaliera 'Santa Maria degli Angeli', 33 I 70 Pordenone, Italy; ${ }^{5}$ Departement of Biomedical \\ Sciences, Università di Catania, 95124 Catania, Italy; ${ }^{6}$ Clinica Otorinolaringoiatrica DNTB, Università degli Studi di Milano Bicocca, 20126 Milan, Italy; \\ 7Unit of Epidemiology, Istituto Tumori 'Fondazione Pascale', IRCCS, 80125 Naples, Italy; ${ }^{8}$ Department of Occupational Health, Università degli Studi di \\ Milano, 20133 Milan, Italy; ${ }^{9}$ International Agency for Research on Cancer, 69372 Lyon, France
}

BACKGROUND: Dietary habits have been related to the risk of nasopharyngeal carcinoma (NPC), but information on a wide range of macro- and micronutrients is still lacking, particularly for low-incidence countries.

METHODS: We conducted a hospital-based case-control study in Italy on 198, histologically confirmed, NPC cases of Caucasian ethnicity of 18-76 years of age. Controls were 594 Caucasian cancer-free patients admitted to general hospitals for acute conditions. Nutrients intake was assessed through a validated food-frequency questionnaire. Adjusted odds ratios (ORs) and the corresponding confidence intervals (Cls) were estimated through logistic regression.

RESULTS: Dietary intake of carotenoids were inversely related to NPC risk, notably carotene (OR for highest vs lowest quartile $=0.46$; 95\% Cl: 0.26-0.79), $\alpha$-carotene ( $\mathrm{OR}=0.57 ; 95 \% \mathrm{Cl}$ : 0.33-0.97), and $\beta$-carotene ( $\mathrm{OR}=0.42 ; 95 \% \mathrm{Cl}$ : 0.24-0.75). Increased NPC risk was observed for elevate cholesterol intake (OR = I.85; $95 \% \mathrm{Cl}:$ ।.12-3.05).

CONCLUSION: Study findings suggest a protective effect of carotenoids against NPC in a low-risk population, adding further support to a possible beneficial role of a diet rich in fruits and vegetables in cancers of the head and neck.

British Journal of Cancer (2012) I 07, I580-1583. doi:I0.1038/bjc.2012.4I3 www.bjcancer.com

Published online II September 2012

(C) 2012 Cancer Research UK

Keywords: nasopharyngeal carcinoma; nutrients; carotenoids; $\alpha$-carotene; $\beta$-carotene

Incidence rates of nasopharyngeal carcinoma (NPC) show wide geographic variations, being 40 -fold more frequent in endemic areas than in Europe and North America (Chang and Adami, 2006). This remarkable heterogeneity may be partly explained by differences in the age at first infection with the Epstein-Barr virus (EBV) (Chang and Adami, 2006), the main cause of undifferentiated NPC. However, the ubiquity of EBV suggests that other risk factors may have a role in NPC aetiology. Notably, wellestablished risk factors for other head and neck carcinomas (i.e., tobacco smoking and alcohol drinking) appear to have a stronger causal role in NPC in low-incidence compared with high-incidence populations including the Italian one (Polesel et al, 2011).

So far, the relationship between NPC risk and diet was investigated in NPC high-risk areas (World Cancer Research Fund/American Institute for Cancer Research, 2007) and in the United States (Farrow et al, 1998, Kasum et al, 2002). However, only three studies considered specific food constituents (Lee et al, 1994, Farrow et al, 1998, Kasum et al, 2002), reporting inverse associations for fibre, vitamin $\mathrm{C}$, vitamin $\mathrm{E}$, and $\beta$-carotene. These findings matched the World Cancer Research Fund/American Institute for

*Correspondence: Dr J Polesel; E-mail: polesel@cro.it

Received 13 April 2012; revised 8 August 2012; accepted 14 August 2012; published online II September 2012
Cancer Research (2007) revision, which concluded that the evidence, although sparse, was generally consistent in showing a negative association with non-starchy vegetables and fresh fruits.

This study investigated the relation between NPC and a wide range of macro- and micronutrients in Italy, a southern European country where NPC is rare.

\section{MATERIALS AND METHODS}

Between 1992 and 2008, we conducted a case-control study on NPC within an established network of collaborating centres, including Aviano (Pordenone) and Milan in northern Italy, and Naples and Catania in southern Italy (Polesel et al, 2011). Study subjects were 198 Caucasian cases, aged 18-76 years (median age: 52 years), admitted for incident and histologically confirmed NPC to major general hospitals in the study areas. They included 137 (68.5\%) undifferentiated NPCs (Shanmugaratnam and Sobin, 1991), 23 (11.5\%) keratinising squamous cell carcinomas (here referred to as differentiated NPCs), and 40 (20\%) not otherwise specified NPCs. EBV status was available for 61 NPC cases based on the detection of EBV nuclear antigen in tissue samples. All 57 undifferentiated NPCs and two out of four differentiated NPCs were EBV-positive.

Three controls were frequency-matched to each case, according to sex, age, and place of residence. The control group included 594 
Caucasian patients (aged 19-76 years; median age: 52 years) admitted for a wide spectrum of acute conditions to the same hospitals as cases. Controls were admitted for traumatic orthopaedic disorders $(34 \%)$, other orthopaedic disorders (32\%), acute surgical conditions (22\%), and miscellaneous other illnesses (12\%). Otherwise, controls admitted for malignant neoplasms, conditions related to tobacco smoking or alcohol consumption, or any other disorder associated to long-term modification of diet were not eligible for this study. All study participants signed an informed consent, according to the recommendations of the Internal Review Boards of each study hospital.

Trained interviewers administered a structured questionnaire to cases and controls during their hospital stay, thus keeping refusal below $3 \%$. The questionnaire collected information on sociodemographic factors, lifestyle habits, smoking and drinking habits, a problem-oriented medical history, and family history of cancer. Usual diet during the two years before interview was investigated through a food-frequency questionnaire specifically targeting the Italian population, including 78 foods or recipes. Subjects were asked to indicate the average weekly consumption of several dietary items. Serving size was defined either in 'natural' units (e.g., one teaspoon of sugar, one egg, one medium apple) or as an average serving in the Italian diet (e.g., $80 \mathrm{~g}$ serving of pasta, $150 \mathrm{~g}$ of red meat, $100 \mathrm{~g}$ of salad). The questionnaire was successfully tested for reproducibility (Franceschi et al, 1993) and validity (Decarli et al, 1996) on a sample of the healthy general population in the study areas. Nutrient supplementation was not assessed in the present study, but it was generally uncommon in the Italian population (Skeie et al, 2009).

Energy and specific nutrient intakes were estimated using an Italian food composition database (Gnagnarella et al, 2004). To evaluate the role of the nutrients independently of total energy intake, energy-adjusted nutrients were derived by residual method (Willett and Stampfer, 1998). The energy-adjusted nutrients were categorised into approximate quartiles according to the distribution among controls; the corresponding odds ratios (ORs) and 95\% confidence intervals (CIs) were estimated using unconditional logistic regression models (Breslow and Day, 1980), adjusting for centre, sex, age, education, place of living, year of interview, nonalcohol energy, and possible confounders (i.e., tobacco smoking and alcohol drinking; Table 1). Results were presented only for major macronutrients, according to animal or vegetal source, and for the most common micronutrients. The test for linear trend was based on the likelihood-ratio test between the models with and without linear terms for each variable of interest (Breslow and Day, 1980).

\section{RESULTS}

NPC risk was positively associated with intake of cholesterol (OR for highest $v s$ lowest quartile $=1.85$; 95\% CI: 1.12-3.05; $P$-trend $=0.01)$ and saturated fatty acids $(\mathrm{OR}=1.75$; $95 \% \mathrm{CI}: 1.04-$ $2.95)$, although the trend in risk for the latter was of borderline significance $(P$-trend $=0.07) \quad($ Table 2$)$. The association with animal fat intake was of borderline statistical significance $(\mathrm{OR}=1.58 ; 95 \%$ CI: $0.96-2.61 ; P$-trend $=0.07)$. No association emerged for other macronutrients.

NPC risk was negatively associated to carotenoids intake (Table 3), notably carotene $(\mathrm{OR}=0.46 ; 95 \%$ CI: $0.26-0.79$; $P$-trend $<0.01), \alpha$-carotene $(\mathrm{OR}=0.57 ; 95 \% \mathrm{CI}: 0.33-0.97)$, and $\beta$-carotene (OR $=0.42 ; 95 \%$ CI: $0.24-0.75)$. Vitamin C intake was also negatively associated with NPC risk (OR $=0.62$; 95\% CI: $0.37-$ 1.04; $P$-trend $=0.06)$, though of borderline significance. Likewise, the results suggested a direct association between elevated phosphorus intake and NPC risk (OR $=1.80 ; 95 \%$ CI: $1.06-3.05)$. Other water-soluble vitamins, minerals, fat-soluble vitamins, and glutathione were not significantly related to NPC risk (Table 3).
Table I Distribution of 198 cases of nasopharyngeal cancer and 594 controls, according to socio-demographic characteristics and selected variables

\begin{tabular}{|c|c|c|c|}
\hline & $\begin{array}{l}\text { Cases } \\
N(\%)\end{array}$ & $\begin{array}{c}\text { Controls } \\
\text { N (\%) }\end{array}$ & \\
\hline \multicolumn{4}{|l|}{ Centre $^{\mathrm{a}}$} \\
\hline Aviano & $150(75.8)$ & $450(75.8)$ & \\
\hline Milan & $48(24.2)$ & $144(24.2)$ & \\
\hline \multicolumn{4}{|l|}{$\operatorname{Sex} x^{\mathrm{a}}$} \\
\hline Men & I 57 (79.3) & 47। (79.3) & \\
\hline Women & $41(20.7)$ & $123(20.7)$ & \\
\hline \multicolumn{4}{|l|}{ Age (years) ${ }^{a}$} \\
\hline$<44$ & $52(26.3)$ & $159(26.7)$ & \\
\hline $45-54$ & $64(32.3)$ & $186(31.3)$ & \\
\hline $55-64$ & $47(23.7)$ & $144(24.2)$ & \\
\hline$\geqslant 65$ & $35(17.7)$ & $105(17.7)$ & \\
\hline \multicolumn{4}{|l|}{ Place of residence $\mathrm{a}^{\mathrm{a}}$} \\
\hline North-East & $90(45.5)$ & $270(45.5)$ & \\
\hline North-West & $48(24.2)$ & $144(24.2)$ & \\
\hline Centre, South, Islands & $60(30.3)$ & $180(30.3)$ & \\
\hline \multicolumn{4}{|l|}{ Education (years) ${ }^{\mathrm{b}}$} \\
\hline$<7$ & $67(33.8)$ & $221(37.3)$ & \\
\hline $7-11$ & $73(36.9)$ & $222(37.5)$ & \\
\hline$\geqslant 12$ & $58(29.3)$ & $149(25.2)$ & \\
\hline$\chi^{2}$ & & & 1.65; $P=0.44$ \\
\hline \multicolumn{4}{|l|}{ Smoking habits ${ }^{\mathrm{b}}$} \\
\hline Never & $60(30.6)$ & $196(33.0)$ & \\
\hline Former & $60(30.6)$ & $181(30.5)$ & \\
\hline \multicolumn{4}{|c|}{ Current (cigarettes per day) } \\
\hline$<15$ & $21(10.7)$ & $78(\mid 3.1)$ & \\
\hline$\chi^{2} \geqslant 15$ & $55(28.1)$ & $139(23.4)$ & 5.97; $P=0.05$ \\
\hline \multicolumn{4}{|c|}{ Alcohol drinking (drinks per week) } \\
\hline$<14$ & $72(36.4)$ & $235(40.3)$ & \\
\hline $14-20$ & $39(19.7)$ & $149(25.1)$ & \\
\hline$\geqslant 21$ & $87(43.9)$ & $210(35.4)$ & \\
\hline$\chi^{2}$ & & & 5.12; $P=0.07$ \\
\hline \multicolumn{4}{|l|}{ Total energy ( $\mathrm{kCal}$ per day) } \\
\hline$<2070$ & $36(18.2)$ & $162(27.3)$ & \\
\hline 2070 to $<2506$ & $43(21.7)$ & $154(25.9)$ & \\
\hline 2506 to $<3030$ & $53(26.7)$ & $146(24.6)$ & \\
\hline$\geqslant 3030$ & $66(33.3)$ & $132(22.2)$ & \\
\hline$\chi^{2}$ & & & $|5.4| ; P<0.0 \mid$ \\
\hline
\end{tabular}

aMatching variable. ${ }^{\text {b}}$ The sum does not add up to total because of missing values.

Dietary findings were similar when analyses were stratified by alcohol drinking and cigarette smoking (data not shown), as well as when undifferentiated NPCs were assessed separately (ORs for highest $v s$ lowest quartile were 2.14 for cholesterol, 0.61 for vitamin C, 0.48 for carotene, 0.73 for $\alpha$-carotene, and 0.44 for $\beta$-carotene).

\section{DISCUSSION}

This study investigated the association between macro- and micronutrients, and the risk of NPC in a southern European population. High intake of cholesterol was associated to increased NPC risk and so was intake of animal fats and saturated fatty acids (borderline statistical significance). Conversely, intake of carotenoids, particularly $\alpha$-carotene and $\beta$-carotene, were negatively associated to NPC risk. Our study findings are consistent with previous work on the topic, showing a negative association between NPC risk and orange/yellow/red pigmented 
Table 2 Energy-adjusted OR for NPC and corresponding 95\% Cl, ${ }^{a}$ according to intake of selected macronutrients, fatty acids, and cholesterol

\begin{tabular}{|c|c|c|c|c|c|c|}
\hline \multirow[b]{2}{*}{ Nutrient } & \multicolumn{4}{|c|}{ Quartile, OR (95\% Cl) } & \multirow[b]{2}{*}{$\chi^{2}$-trend } & \multirow[b]{2}{*}{ Continuous OR $(95 \% \mathrm{Cl})^{c}$} \\
\hline & $\overline{\mathbf{I}^{\mathbf{b}}}$ & II & III & IV & & \\
\hline \multicolumn{7}{|l|}{ Macronutrients } \\
\hline Vegetal proteins & । & $1.01(0.62-1.64)$ & $0.94(0.57-1.56)$ & $0.80(0.48-1.33)$ & $P=0.39$ & $0.77(0.56-1.06)$ \\
\hline Animal fats & i & $1.03(0.60-1.75)$ & $1.02(0.59-1.76)$ & $1.58(0.96-2.61)$ & $P=0.07$ & $1.43(1.12-1.83)$ \\
\hline Vegetal fats & i & $1.17(0.70-1.95)$ & $1.27(0.77-2.10)$ & $0.82(0.50-1.36)$ & $P=0.54$ & $0.82(0.66-1.04)$ \\
\hline \multicolumn{7}{|l|}{ Fatty acids and cholesterol } \\
\hline Saturated fatty acids & । & $1.55(0.9 \mid-2.65)$ & $1.35(0.78-2.32)$ & $1.75(1.04-2.95)$ & $P=0.07$ & $1.44(1.08-1.92)$ \\
\hline Monounsaturated fatty acids & । & $1.04(0.61-1.77)$ & $1.07(0.63-1.82)$ & $0.98(0.59-1.60)$ & $P=0.93$ & $0.91(0.71-1.16)$ \\
\hline Polyunsaturated fatty acids & i & $0.94(0.56-1.58)$ & $1.21(0.7 \mid-2.04)$ & $1.11(0.66-1.87)$ & $P=0.54$ & $0.96(0.77-1.20)$ \\
\hline Cholesterol $^{d}$ & 1 & $1.11(0.65-1.89)$ & $1.13(0.65-1.94)$ & $1.85(1.12-3.05)$ & $P=0.01$ & $1.40(1.08-1.81)$ \\
\hline
\end{tabular}

Abbreviations: $\mathrm{Cl}=$ confidence interval; $\mathrm{NPC}=$ nasopharyngeal carcinoma; $\mathrm{OR}=$ odds ratio. ${ }^{\mathrm{a} E s t i m a t e d}$ by unconditional logistic regression model, adjusted for centre, sex, age, place of living, year of interview, education, tobacco smoking, alcohol drinking, and non-alcohol energy. Adjustment for energy was made according to residual model. ${ }^{\text {b Reference }}$

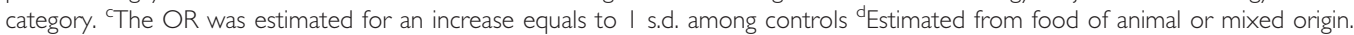

Table 3 Energy-adjusted OR for NPC and corresponding 95\% Cl, ${ }^{a}$ according to intake of selected minerals, vitamins, carotenoids, and glutathione

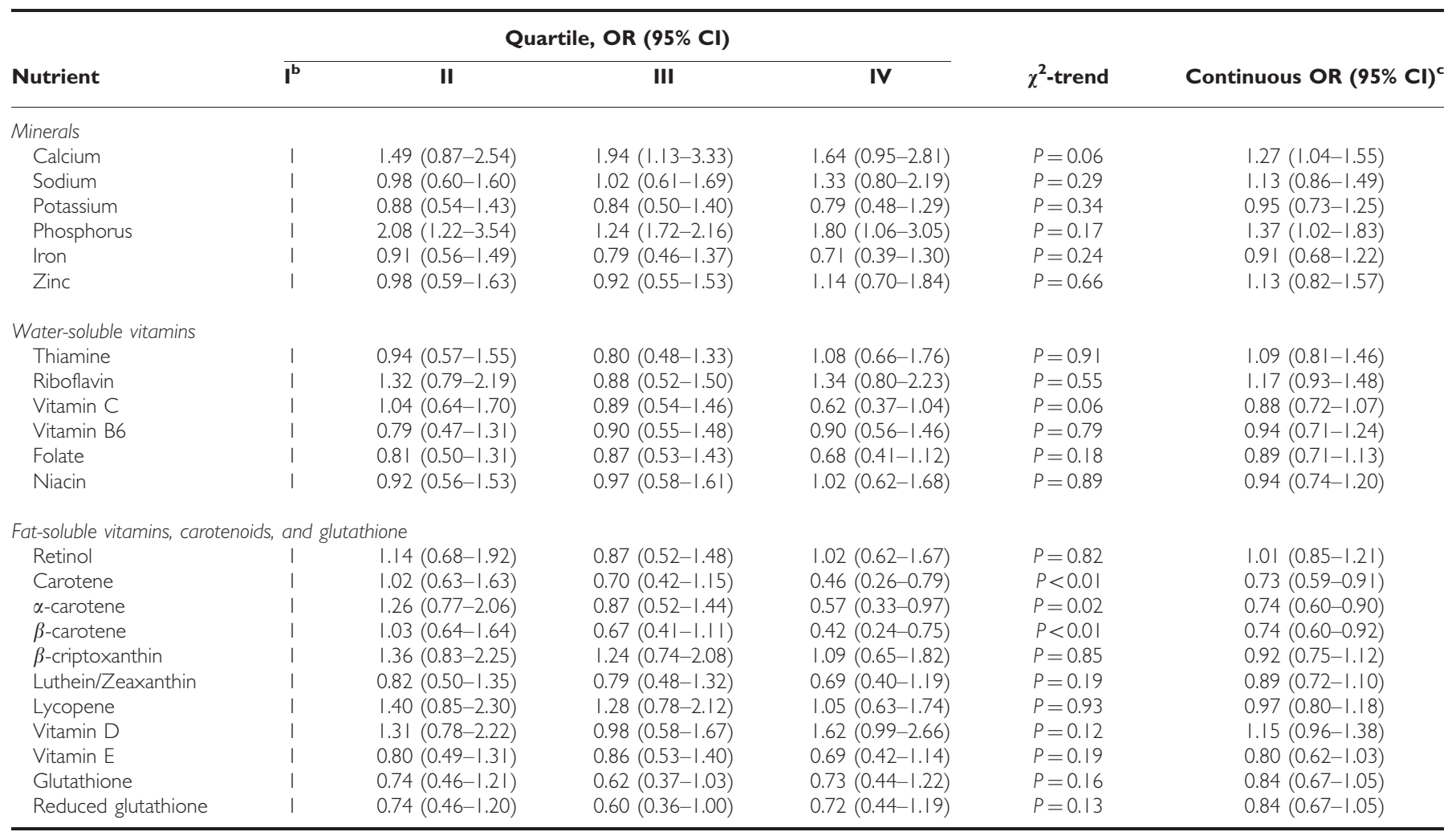

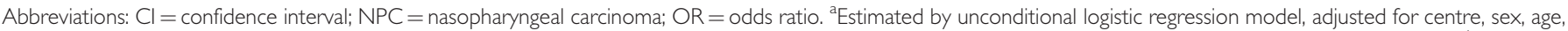
place of living, year of interview, education, tobacco smoking, alcohol drinking, and non-alcohol energy. Adjustment for energy was made according to residual model. ${ }^{b}$ Reference category. 'The OR was estimated for an increase equals to I s.d. among controls.

vegetables (i.e., carotenoid-rich foods) (Armstrong et al, 1998; Yaun et al, 2000; Kasum et al, 2002).

An inverse association between carotenoids intake and cancer risk was consistently reported for other epithelial cancers of the aero-digestive tract, such as mouth, pharynx, larynx, oesophagus, and lung (World Cancer Research Fund/American Institute for Cancer Research, 2007). Carotenoids are well-known antioxidants with anti-mutagenic and immune-regulatory actions (Krinsky, 1991; Chew and Park, 2004).
Elevated dietary cholesterol has been associated to excess risk of several cancers ( $\mathrm{Hu}$ et al, 2011). Mechanisms have been proposed to explain the possible role of cholesterol in cancer development, including cellular inflammation due to alterations in lipid and apolipoprotein levels (Ferretti et al, 2006), and increased levels of proinflammatory cytokines (Haddy et al, 2003). However, the present results should be interpreted with caution, as no information on different serum lipoproteins were available for our study, and elevated cholesterol intake could be an indicator 
that a diet rich in meat, eggs, and dairy products may have unfavourable effects.

The lack of information on EBV status in the majority of NPC cases was a weakness of the present study. In the subset of cases with available EBV information, all undifferentiated NPCs were EBV-positive, suggesting that EBV should not be considered a confounder. In addition, when we assessed EBV-related undifferentiated NPCs separately, similar associations emerged with intake of carotenoids and cholesterol, as in the overall analyses.

The ability of food-frequency questionnaires to estimate circulating nutrient levels is an additional concern in a dietary study. However, the results from the EPIC study suggested that intakes of specific food items as measured by questionnaires are good predictors of plasma concentrations of some nutrients, carotenoids in particular (Al-Delaimy et al, 2005).

Other potential limitations of this study include the relatively small sample size, and possible information and selection biases. Because of the rarity of NPC in Italy, yielding an adequate sample size in a reasonable length of time was a challenge. Vis-a-vis interview of cases and controls by the same trained interviewers, under similar conditions in a hospital setting, minimised information bias. Careful attention was also paid to exclude from the control group subjects admitted for any condition that might have induced modification of the usual diet. In addition, the almost complete case ascertainment in the catchment areas, the nearly complete participation of identified cases and controls, and the use of a validated and reproducible questionnaire (Franceschi et al, 1993; Decarli et al, 1996) contributed to strengthen our findings.

\section{REFERENCES}

Al-Delaimy WK, Ferrari P, Slimani N, Pala V, Johansson I, Nilsson S, Mattisson I, Wirfalt E, Galasso R, Palli D, Vineis P, Tumino R (2005) Plasma carotenoids as biomarkers of intake of fruits and vegetables: individual-level correlations in the European Prospective Investigation into Cancer and Nutrition (EPIC). Eur J Clin Nutr 59: 1387-196

Armstrong RW, Imrey PB, Lye MS, Armstrong MJ, Yu MC, Sani S (1998) Nasopharyngeal carcinoma in Malaysian Chinese: salted fish and other dietary exposures. Int J Cancer 77: 228-235

Breslow NE, Day NE (1980) Statistical Methods in Cancer Research, Vol I: The Analysis of Case-Control Studies. IARC Scientific Publications No. 32: Lyon

Chang ET, Adami HO (2006) The enigmatic epidemiology of nasopharyngeal carcinoma. Cancer Epidemiol Biomarker Prev 15: 1765-1777

Chew BP, Park JS (2004) Carotenoid action on the immune response. J Nutr 134: 257S-261S

Decarli A, Franceschi S, Ferraroni M, Gnagnarella P, Parpinel MT, La Vecchia C, Negri E, Salvini S, Falcini F, Giacosa A (1996) Validation of a food-frequency questionnaire to asses dietary intakes in cancer studies in Italy. Results for specific nutrients. Ann Epidemiol 6: $110-118$

Farrow DC, Vaughan TL, Berwick M, Lynch CF, Swanson GM, Lyon JL (1998) Diet and nasopharyngeal cancer in a low-risk population. Int J Cancer 78: 675-679

Ferretti G, Bacchetti T, Nègre-Salvayre A, Salvayre R, Dousset N, Curatola G (2006) Structural modification of HDL and functional consequences. Atherosclerosis 184: 1-7

Franceschi S, Negri E, Salvini S, Decarli A, Ferraroni M, Filiberti R, Giacosa A, Talamini R, Nanni O, Panarello G, La Vecchia C (1993) Reproducibility of an Italian food frequency questionnaire for cancer studies. Results for food items. Eur J Cancer 29A: 2298-2305

Gnagnarella P, Parpinel M, Salvini S, Franceschi S, Palli D, Boyle P (2004) The update of the Italian Food Composition Database. J Food Comp Anal 17: $509-522$

Haddy N, Sass C, Droesch S, Zaiou M, Siest G, Ponthieux A, Lambert D, Visvikis S (2003) IL-6, TNF-alpha and atherosclerosis risk indicators in a healthy family population: the STANISLAS cohort. Atherosclerosis 170: 277-283
In conclusion, our investigation revealed a protective effect of carotenoids against NPC in low-incidence populations, supporting the beneficial role of a diet rich in fruits and vegetables in head and neck cancers. Similar results on $\beta$-carotene were reported in Singapore Chinese (Lee et al, 1994), suggesting that our findings could be extended to populations at high risk for NPC.

\section{ACKNOWLEDGEMENTS}

This work was supported by the Italian Association for Research on Cancer (AIRC). We thank Mrs O Volpato for study coordination and L Mei for editorial assistance. We are also deeply grateful to Dr Emilia De Santis for the revision of the histopathological diagnoses; Drs Giovanni Franchin (Radiation Oncology Division, Centro di Riferimento Oncologico, Aviano) and Emanuela Vaccher (Medical Oncology A Division, Centro di Riferimento Oncologico, Aviano) for cases ascertainment; Drs G Chiara (1st General Surgery Department, General Hospital, Pordenone), G Tosolini (2nd General Surgery Department, General Hospital, Pordenone), L Forner (Eye Diseases Department, General Hospital, Pordenone), A Mele (Hand Surgery and Microsurgery Department, General Hospital, Pordenone), and E Trevisanutto (Dermatology Department, General Hospital, Pordenone) for helping in the enrolment of controls.

\section{Conflict of interest}

The authors declare no conflict of interest.

Hu J, La Vecchia C, de Groh M, Negri E, Morrison H, Mery H, Mery L, Canadian Cancer Registries Epidemiology Research Group (2011) Dietary cholesterol intake and cancer. Ann Oncol 23: 491-500

Kasum CM, Jacobs DR, Nicodemus K, Folsom AR (2002) Dietary risk factors for upper aerodigestive tract cancers. Int J Cancer 99: 267-272

Krinsky NI (1991) Effect of carotenoids in cellular and animal systems. Am J Clin Nutr 53: 238S-246S

Lee HP, Gourley L, Duffy SW, Esteve J, Lee J, Day NE (1994) Preserved foods and nasopharyngeal carcinoma: a case-control study among Singapore Chinese. Int J Cancer 59: 585-590

Polesel J, Franceschi S, Talamini R, Negri E, Barzan L, Montella M, Libra M, Vaccher E, Franchin G, La Vecchia C, Serraino D (2011) Tobacco smoking, alcohol drinking, and the risk of different histological types of nasopharyngeal cancer in a low-risk population. Oral Oncol 47: 541-545

Shanmugaratnam K, Sobin LH (1991) Histological Typing of Tumours of the Upper Respiratory Tract and Ear. 2nd edn. Springer-Verlag: Berlin, Germany

Skeie G, Braaten T, Hjartaker A, Lentjes M, Amiano P, Jakszyn P, Pala V, Palanca A, Niekerk EM, Verhagen H, Avloniti K, Psaltopoulou T, Niravong M, Touvier M, Nimptsch K, Haubrock J, Walker L, Spencer EA, Roswall N, Olsen A, Wallström P, Nilsson S, Casagrande C, Deharveng G, Hellström V, Boutron-Ruault MC, Tjønneland A, Joensen AM, ClavelChapelon F, Trichopoulou A, Martinez C, Rodríguez L, Frasca G, Sacerdote C, Peeters PHM, Linseisen J, Schienkiewitz A, Welch AA, Manjer J, Ferrari P, Riboli E, Bingham S, Engeset D, Lund E, Slimani N (2009) Use of dietary supplements in the Europe Prospective Investigation into Cancer and Nutrition calibration study. Eur J Clin Nutr 63: S226-S238

Willett WC, Stampfer MJ (1998) Implication of total energy intake for epidemiologic analyses. In: Nutritional Epidemiology. 2nd edn pp. 273-301. Oxford University Press: New York, USA

World Cancer Research Fund/American Institute for Cancer Research (2007) Food, Nutrition, Physical Activity, and the Prevention of Cancer: A Global Perspective. pp 250-252. AICR: Washington DC, US

Yaun JM, Wang XL, Xiang YB, Gao YT, Ross RK, Yu MC (2000) Preserved foods in relation to risk of nasopharyngeal carcinoma in Shanghai, China. Int J Cancer 85: 358-363 